\title{
Influence of enamel/dentin thickness on the toxic and esthetic effects of experimental in-office bleaching protocols
}

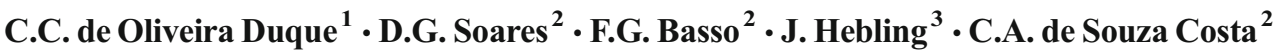

Received: 16 May 2016 / Accepted: 4 January 2017 / Published online: 14 January 2017

(C) Springer-Verlag Berlin Heidelberg 2017

\begin{abstract}
Objectives This paper aims to assess the whitening effectiveness and toxicity of tooth-bleaching protocols applied to enamel/dentin disks simulating mandibular incisors (ICs) and premolars (PMs).

Materials and methods A $10 \%$ hydrogen peroxide $\left(\mathrm{H}_{2} \mathrm{O}_{2}\right)$ gel was applied for $3 \times 15,1 \times 15$, or $1 \times 5 \mathrm{~min}$ to enamel/dentin disks simulating mandibular ICs and PMs, and the trans-enamel and trans-dentinal diffusion products were applied to human dental pulp cells $(1 \mathrm{~h})$. Professional therapy $\left(35 \% \mathrm{H}_{2} \mathrm{O}_{2}-\right.$ $3 \times 15 \mathrm{~min}$ ) was used as positive control, and non-bleached samples were used as negative control. Cell viability and morphology, oxidative stress generation, and odontoblastic marker expression were assessed. The $\mathrm{H}_{2} \mathrm{O}_{2}$ diffusion and enamel color change $(\Delta E)$ were also analyzed.

Results The $10 \% \mathrm{H}_{2} \mathrm{O}_{2}$ gel induced significant cell viability reduction only when applied $3 \times 15 \mathrm{~min}$, with the intensity of oxidative stress and down-regulation of odontoblastic markers being higher in the IC group. The other experimental bleaching protocols caused slight alterations regarding the cell parameters evaluated, with intensity being related to enamel/dentin thickness. These effects were also correlated with higher $\mathrm{H}_{2} \mathrm{O}_{2}$
\end{abstract}

\section{C.A. de Souza Costa}

casouzac@foar.unesp.br

1 Department of Dental Materials and Prosthodontics, Araraquara School of Dentistry, Univ. Estadual Paulista - UNESP, Humaitá Street, 1680, Araraquara, SP 14801-903, Brazil

2 Department of Physiology and Pathology, Araraquara School of Dentistry, Univ. Estadual Paulista - UNESP, Humaitá Street, 1680, Araraquara, SP 14801-903, Brazil

3 Department of Orthodontics and Pediatric Dentistry, Araraquara School of Dentistry, Univ. Estadual Paulista - UNESP, Humaitá Street, 1680, Araraquara, SP 14801-903, Brazil diffusion in the IC group. $\Delta E$ values similar as positive control were found for the $10 \% 3 \times 15$ and $1 \times 15$ protocols on IC group, after 4 and 6 sessions.

Conclusion Application of a $10 \% \mathrm{H}_{2} \mathrm{O}_{2}$ bleaching gel for 15 or $45 \mathrm{~min}$ to thin dental substrate significantly minimizes cell toxicity in comparison with highly concentrated gels associated with similar esthetic outcomes by increasing the number of bleaching sessions.

Clinical relevance Bleaching gels with $10 \% \mathrm{H}_{2} \mathrm{O}_{2}$ applied in small teeth for short periods may be an interesting alternative to obtain whitening effectiveness without causing toxicity to pulp cells, which may be able to reduce the tooth hypersensitivity claimed by patients.

Keywords Tooth bleaching $\cdot$ Dental pulp $\cdot$ Cytotoxicity $\cdot$ Cell differentiation

\section{Introduction}

Randomized clinical trials have detected that tooth hypersensitivity following bleaching therapies is limited to anterior teeth, with the intensity of this adverse effect being directly related to the thickness of enamel and dentin [1,2]. Rodrigues et al. [3] demonstrated that the permeability of canines and incisors was significantly increased after bleaching with a $38 \%$ hydrogen peroxide $\left(\mathrm{H}_{2} \mathrm{O}_{2}\right)$ gel, whereas premolars showed no or slight alteration. Indeed, histopathological studies in human teeth have shown that in-office bleaching with 35-38\% $\mathrm{H}_{2} \mathrm{O}_{2}$ gels causes intense damage to pulp tissue of mandibular incisors, characterized by tissue disorganization, disturbance of the odontoblastic layer, areas of necrosis, and intense inflammatory reaction $[4,5]$. Conversely, premolars subjected to the same bleaching therapy did not exhibit such remarkable histological pulp alterations $[6,7]$. 
The intensity of pulp cells damage mediated by bleaching gels has been correlated with the amount of residual $\mathrm{H}_{2} \mathrm{O}_{2}$ capable of diffusing through enamel and dentin to reach the pulp chamber [8]. It is believed that the amount of $\mathrm{H}_{2} \mathrm{O}_{2}$ that reaches the pulp chamber is proportional to the enamel/dentin thickness of bleached teeth; therefore, small teeth, such as mandibular incisors, are more susceptible to the adverse effects of $\mathrm{H}_{2} \mathrm{O}_{2}$ released from bleaching gels. In view of this, it seems reckless to apply the same current professional bleaching protocols for different teeth disregarding their enamel and dentin thicknesses. Recent studies have demonstrated that 8 and $10 \% \mathrm{H}_{2} \mathrm{O}_{2}$ bleaching gels resulted in limited trans-enamel and trans-dentinal cytotoxicity to human dental pulp cells in vitro, especially when the products were applied for $15 \mathrm{~min}$ to enamel/dentin disks simulating the thickness of maxillary central incisors [9]. Therefore, the aim of the present investigation was to assess the influence of enamel/dentin thickness on the bleaching effectiveness and cytotoxicity of a $10 \% \mathrm{H}_{2} \mathrm{O}_{2}$ gel applied on tooth surface for different periods.

\section{Materials and methods}

\section{Enamel/dentin disks}

First, sound human mandibular central incisors (ICs) and maxillary premolars (PMs) with no pulpal atresia were collected $(n=4)$ (Research Ethics Committee of the Araraquara School of Dentistry-UNESP, Araraquara, São Paulo, Brazil; CAAE 3,467,314.0.0000.5416), for measurement of enamel and dentin thickness. These teeth were selected based on the histopathological findings of de Souza Costa et al. [7], who demonstrated that professional in-office bleaching therapy $\left(38 \% \mathrm{H}_{2} \mathrm{O}_{2}\right.$, $3 \times 10 \mathrm{~min}$ ) caused intense inflammatory reaction in pulp tissue of mandibular incisors, whereas slight or no pulp changes were detected in premolars subjected to the same therapy.
Longitudinal cuts were performed at the central portions of incisors and premolar crowns with a diamond disk (11-4254, $4 " \times 0.012 " /$ series 15LC, Diamond Blade, Buehler Ltd., Lake Bluff, IL, USA) mounted in a metallographic cutter (ISOMET 1000, Buehler Ltd.). Representative images of each tooth half were obtained by means of a stereoscopic loupe (SZX7 Olympus, São Paulo, Brazil). The enamel and dentin thicknesses were measured with ImageJ software (National Institutes of Health), by means of a straight line from the enamel surface to the dentino-enamel junction and from the enamel surface to the top of the buccal pulp horn. Dentin thickness was obtained by subtracting enamel thickness from enamel/dentin thickness values (Fig. 1). The pulpal horn was chosen as a reference point since previously histopathological studies demonstrated the presence of necrosis at this area on human mandibular incisors subjected to bleaching $[4,5,7]$. Therefore, the smallest distance from the top of the pulp horn to the buccal surface was selected to represent the fastest pathway for the $\mathrm{H}_{2} \mathrm{O}_{2}$ diffusion to reach the pulp chamber. According to the results, the total enamel/dentin thickness of mandibular central ICs was $2.29 \pm 0.16 \mathrm{~mm}$ (enam$\mathrm{el}=0.80 \pm 0.14 \mathrm{~mm}$; dentin $=1.49 \pm 0.14 \mathrm{~mm}$ ). For the maxillary PMs, the total enamel/dentin thickness was $4.00 \pm 0.60 \mathrm{~mm}$ (enamel $=1.71 \pm 0.47 \mathrm{~mm}$; dentin $=2.44 \pm 0.33 \mathrm{~mm})$.

Based on these data, 140 enamel/dentin disks $(5.6 \mathrm{~mm}$ in diameter) were obtained from the buccal surfaces of bovine incisors, as previously described [9], and distributed into two major groups according to the enamel/dentin thicknesses, IC group-enamel/dentin thickness $=2.30 \pm 0.2 \mathrm{~mm}$ (enamel $=0.97 \pm 0.10 \mathrm{~mm}$, dentin $=1.33 \pm 0.10 \mathrm{~mm})$ and $\mathrm{PM}$ group - enamel $/$ dentin thickness $=4.00 \pm 0.20 \mathrm{~mm}$ (enam$\mathrm{el}=1.05 \pm 0.10 \mathrm{~mm}$, dentin $=2.95 \pm 0.1 \mathrm{~mm}$ ) (Fig. 2). Since the enamel of bovine incisors $(1.05 \mathrm{~mm})$ was thinner than that found in human premolars $(1.71 \mathrm{~mm})$, the dentin thickness was increased for PM group in order to standardize the total enamel/dentin thickness in $4.00 \mathrm{~mm}$.
Fig.1 Representative images for measurement of enamel $(E)$ and enamel/dentin $(E+D)$ thickness on human incisors (a) and premolars (b). Asterisk denotes top of the buccal pulp horn

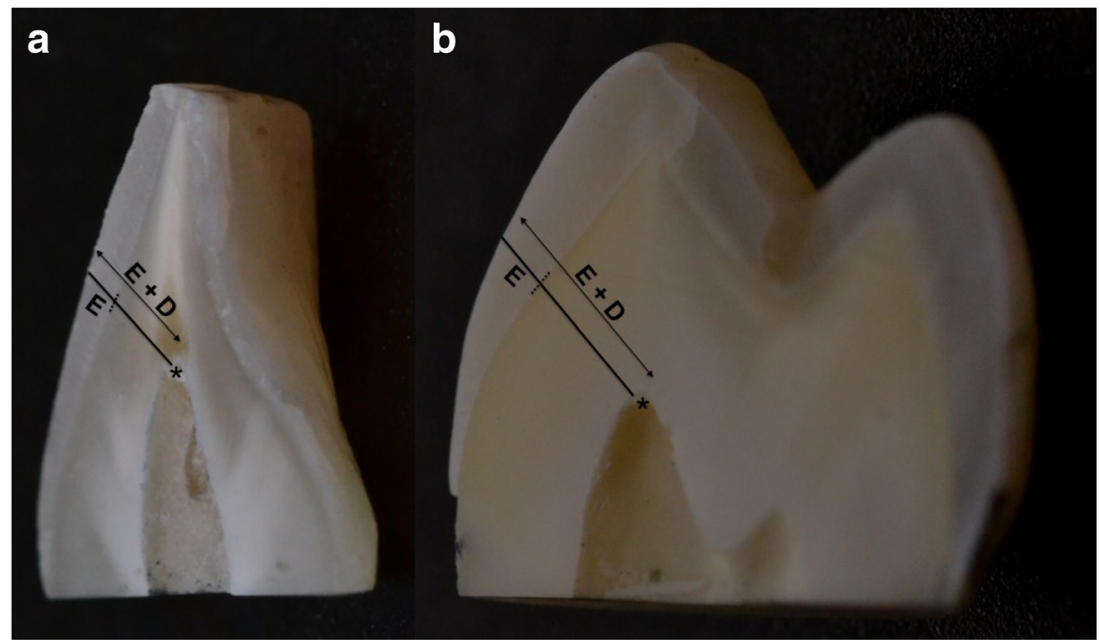


Fig. 2 Representative images of enamel/dentin disks from bovine incisors of IC (a) and PM (b) groups

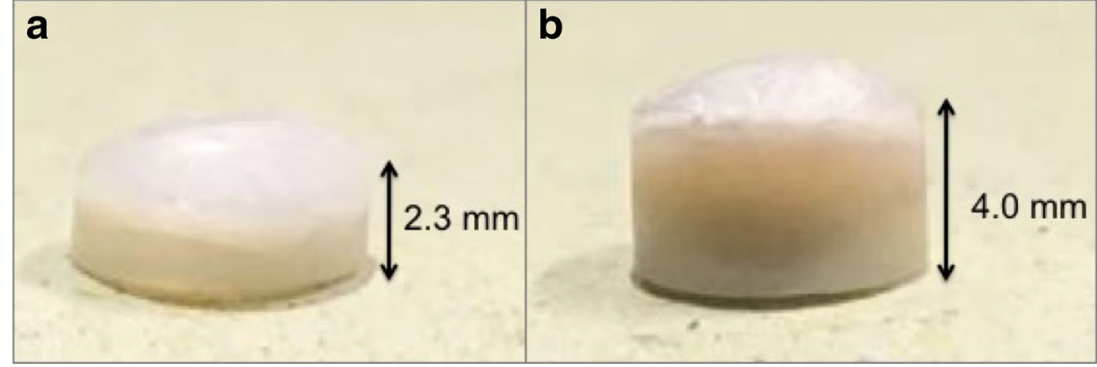

To achieve the established total enamel/dentin thickness, the dentin surface was ground wet with 400- and 600-grit silicon carbide papers (T469-SF; Norton, Saint-Gobam Abrasivos Ltda., Jundiaí, SP, Brazil) followed by treatment with $0.5 \mathrm{M}$ ethylenediaminetetraacetic acid solution (EDTA), $\mathrm{pH} 7.2$, for $30 \mathrm{~s}$, to selectively remove the smear layer without opening dentinal tubules diameter [10]. The enamel surface was cleaned with a solution of pumice stone and distilled water at low speed for removal of any superficial staining.

\section{Cell culture}

A primary culture of human dental pulp cells was obtained from sound third molars obtained from a young donor (20 years old), after signing the donation form approved by the Ethics Committee of Araraquara School of Dentistry, SP, Brazil (CAAE 3,467,314.0.0000.5416). Immediately after the teeth were collected, the pulp tissue was removed and incubated with type I collagenase solution ( $3 \mathrm{mg} / \mathrm{mL}$; Worthington Biochemical Corporation, Lakewood, NJ, USA) to promote enzymatic dissociation [6]. After that, the cells were cultivated in Dulbecco's modified Eagle medium (DMEM) supplemented with $100 \mathrm{IU} / \mathrm{mL}$ and $100 \mu \mathrm{g} / \mathrm{mL}$ of penicillin and streptomycin, respectively, and $2 \mathrm{mmol} / \mathrm{L}$ of glutamine; GIBCO, Grand Island, NY, USA) containing $10 \%$ fetal bovine serum (FBS; GIBCO). Identification of stem cells on HDPC culture was performed by immunofluorescence assay for STRO-1 and CD-146, as previously described [9]. Positive staining for the primary antibodies tested (Fig. 3) indicated that the
HDPC culture used in this investigation presents a subpopulation of mesenchymal stem cells [11]. Cells at passages \#4 to \#6 were used in this experiment.

\section{Experimental procedure}

The disks were adapted to artificial pulp chambers (APCs) by means of silicon $\mathrm{O}$ rings, and the region surrounding the disks and the lateral walls of the APCs was sealed with wax, as previously described [9, 10]. The APC/disk sets were sterilized in ethylene oxide and then placed in wells of 24-well plates containing $1 \mathrm{~mL}$ of DMEM with no FBS, such that the dentin surface was in direct contact with the culture medium and the enamel faced up. The experimental groups are shown in Table 1. In negative control, no treatment was performed on enamel (considered as $100 \%$ of cell activity parameters). The professional in-office bleaching protocol (application of a $35 \% \mathrm{H}_{2} \mathrm{O}_{2}$ bleaching gel, three times for $15 \mathrm{~min}$ each; FGM, Joinville, SC, Brazil) was used as positive control.

The $10 \% \mathrm{H}_{2} \mathrm{O}_{2}$ bleaching gel was obtained by dilution of the $35 \% \mathrm{H}_{2} \mathrm{O}_{2}$ gel in sterile distilled water. Immediately after teeth were bleached, the APC/disk set was removed from the well, and the culture medium (extract) was collected and distributed into aliquots of $100 \mu \mathrm{L}$, which were then applied to the HDPCs previously seeded onto wells (10,000 cells/well) of 96-well plates. The cells were incubated at $37{ }^{\circ} \mathrm{C}$ and $5 \%$ $\mathrm{CO}_{2}$ for $1 \mathrm{~h}$ in contact with the extracts. Cell analysis were performed at distinct periods following extract exposure: T1 $(0 \mathrm{~h})$-immediately after the 1 -h incubation time with the
Fig. 3 Immunofluorescence staining for mesenchymal stem cells markers. Green fluorescence indicates positive staining for the stem cells markers CD-146, Oct $3 / 4$, and STRO-1, and blue fluorescence indicates the nucleus

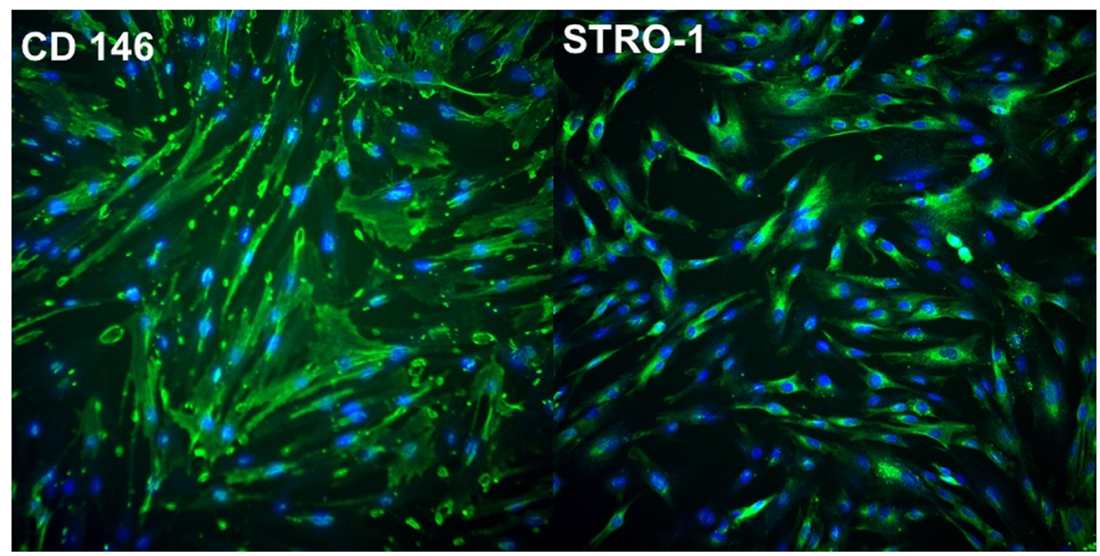


Table 1 Description of experimental groups

\begin{tabular}{lllll}
\hline Experimental groups & Tooth group & $\begin{array}{l}\text { Enamel/dentin } \\
\text { thickness }\end{array}$ & $\begin{array}{l}\text { Bleaching gel } \\
\text { concentration }\end{array}$ & $\begin{array}{l}\text { Application } \\
\text { protocol (min) }\end{array}$ \\
\hline Control IC & IC & $2.3 \mathrm{~mm}$ & No gel & - \\
$35 \% 3 \times 15 \mathrm{IC}$ & $\mathrm{IC}$ & $2.3 \mathrm{~mm}$ & $35 \% \mathrm{H}_{2} \mathrm{O}_{2}$ & $3 \times 15$ \\
$10 \% 3 \times 15 \mathrm{IC}$ & $\mathrm{IC}$ & $2.3 \mathrm{~mm}$ & $10 \% \mathrm{H}_{2} \mathrm{O}_{2}$ & $3 \times 15$ \\
$10 \% 1 \times 15 \mathrm{IC}$ & IC & $2.3 \mathrm{~mm}$ & $10 \% \mathrm{H}_{2} \mathrm{O}_{2}$ & $1 \times 15$ \\
$10 \% 1 \times 5 \mathrm{IC}$ & $\mathrm{IC}$ & $2.3 \mathrm{~mm}$ & $10 \% \mathrm{H}_{2} \mathrm{O}_{2}$ & $1 \times 5$ \\
$\mathrm{Control} \mathrm{PM}$ & $\mathrm{PM}$ & $4.0 \mathrm{~mm}$ & $\mathrm{Nogel}$ & - \\
$35 \% 3 \times 15 \mathrm{PM}$ & $\mathrm{PM}$ & $4.0 \mathrm{~mm}$ & $35 \% \mathrm{H}_{2} \mathrm{O}_{2}$ & $3 \times 15$ \\
$10 \% 3 \times 15 \mathrm{PM}$ & $\mathrm{PM}$ & $4.0 \mathrm{~mm}$ & $10 \% \mathrm{H}_{2} \mathrm{O}_{2}$ & $3 \times 15$ \\
$10 \% 1 \times 15 \mathrm{PM}$ & $\mathrm{PM}$ & $4.0 \mathrm{~mm}$ & $10 \% \mathrm{H}_{2} \mathrm{O}_{2}$ & $1 \times 15$ \\
$10 \% 1 \times 5 \mathrm{PM}$ & $\mathrm{PM}$ & $4.0 \mathrm{~mm}$ & $10 \% \mathrm{H}_{2} \mathrm{O}_{2}$ & $1 \times 5$ \\
\hline
\end{tabular}

extracts and T2 (72 h) - the extract was aspirated after the 1-h incubation time, and the cells were cultured with $200 \mu \mathrm{L}$ of DMEM supplemented with $10 \%$ FBS for an additional $72 \mathrm{~h}$; and T3 (14 days) and T4 (21 days) - after extract exposure, the cells were cultured with $200 \mu \mathrm{L}$ of osteogenic medium (DMEM plus $10 \% \mathrm{FBS}$, supplemented with $10 \mathrm{nmol} / \mathrm{L} \beta$ glycerophosphate and $50 \mu \mathrm{g} / \mathrm{mL}$ sodium ascorbate; Sigma Chemical Co., St. Louis, MO, USA) for 14 and 21 days, respectively (the culture medium was changed every $48 \mathrm{~h}$ ). The time points selected for ALP activity (T3) and mineralized nodule deposition (T4) represent the peak of activity for each marker, as previously demonstrated by Soares et al. [12].

In total, six APC/disk sets $(n=6)$ were used for each group, in which cell viability, oxidative stress, ALP activity, and mineralized matrix deposition were assessed and $\mathrm{H}_{2} \mathrm{O}_{2}$ diffusion was quantified. Two additional APC/disk sets per group were prepared for cell morphology analysis. For this protocol, the HDPCs were seeded onto glass slides placed at the bottom of wells of 24-well plates at $80 \%$ confluence $(60,000$ cells/well; $24 \mathrm{~h}$ ), and a $500 \mu \mathrm{L}$ quantity of extracts was collected and applied to the cultured cells for $1 \mathrm{~h}$.

\section{Cell viability}

The cell viability was determined by MTT assay $(n=6)$ at T1 and T2. Briefly, the cells were incubated with DMEM supplemented with $5 \mathrm{mg} / \mathrm{mL}$ MTT salt (Sigma Chemical Co.) (10:1) for $4 \mathrm{~h}$ at $37^{\circ} \mathrm{C}$ and $5 \% \mathrm{CO}_{2}$. Then, the formazan crystals were dissolved, and the absorbance was read at $570 \mathrm{~nm}$ (Synergy H1, Biotek, Winooski, VT, USA). For both dental structure thicknesses, the mean absorbance value of the negative control group was considered as $100 \%$ of cell viability $[8,9]$.

\section{Cell morphology}

At T1 and T2 $(n=2)$, the remaining cells attached to the glass slides were fixed in $2.5 \%$ glutaraldehyde, post-fixed in $1 \%$ osmium tetroxide (Sigma Chemical Co.), dehydrated in ethanol (30, 50, 70, 95, and $100 \%)$, and subjected to chemical drying with 1,1,1,3,3,3-hexamethyldisilazane (HMDS; Sigma Chemical Co.). After $72 \mathrm{~h}$ in a desiccator, the samples were covered with gold and analyzed by scanning electron microscopy (JEOL JSM 6610; JEOL Ltd., Akishima, Tokyo, Japan) $[8,9]$.

\section{Oxidative stress measurement}

The production of reactive oxygen species (ROS) in cultured cells was quantified at $\mathrm{T} 1$ by means of a cell-permeant fluorescence probe, 6-carboxy-2',7'-dichlorodihydrofluorescein diacetate (carboxy- $\mathrm{H}_{2}$ DCFDA) (Life Technologies, San Francisco, CA, USA) $(n=6)$. The cells were incubated at $37^{\circ} \mathrm{C}$ and $5 \% \mathrm{CO}_{2}$ with $5 \mu \mathrm{M}$ carboxy- $\mathrm{H}_{2}$ DCFDA for $10 \mathrm{~min}$ and then exposed for $1 \mathrm{~h}$ to the extracts $(100 \mu \mathrm{L})$ of each experimental group. After this period, the fluorescence intensity was monitored at 592-nm excitation and 517-nm emission by means of a microplate fluorescence reader (Synergy H1, Biotek).

\section{Alkaline phosphatase activity}

This analysis was performed at T3 by means of a standard kit for ALP measurement (end point assay; Labtest, Lagoa Santa, MG, Brazil), as previously described in detail by Soares et al. [10] $(n=6)$. Briefly, cell lysis was performed $(0.1 \%$ sodium lauryl sulfate; Sigma), and an aliquot was transferred to tubes containing thymolphthalein monophosphate substrate at $37^{\circ} \mathrm{C}$. After a 10 min incubation period at $37^{\circ} \mathrm{C}$, the color reagent (sodium carbonate and sodium hydroxide) was added, and the absorbance was read at a 590-nm wavelength (Synergy H1, Biotek), which was converted into U/L by means of a standard curve. Total protein (TP) dose was performed for normalization of ALP according to the Read and Northcote protocol, as previously described [10]. The absorbance of the test and blank tubes was measured at a 655-nm wavelength (Synergy H1, Biotek) and converted into $\mathrm{mg} / \mathrm{L}$ by a standard protein curve. The final value of ALP was normalized by total protein obtained from each well, with the value 
of ALP activity as U/mg of protein. The mean ALP activity value of the control group was considered as $100 \%$ of ALP activity, and the percentage value for each sample was calculated based on this parameter and used for statistical analysis.

\section{Mineralized nodule deposition}

For assessment of the quantity of mineralized matrix deposited $(n=6)$, Alizarin Red staining was performed at T4. The cells were fixed with $70 \%$ ethanol at $4^{\circ} \mathrm{C}$ for $1 \mathrm{~h}$, washed with deionized water, and then stained with Alizarin Red dye (40 mM, pH 4.2; Sigma Chemical Co.) for $20 \mathrm{~min}$, under gentle shaking (VDR Shaker, Biomixer, Ribeirão Preto, SP, Brazil). After aspiration of unincorporated dye, the cells were washed twice with deionized water for the removal of excess stain. The cells were then incubated with $10 \%$ cetylpyridinium chloride (Sigma Chemical Co.) for 15 min under agitation to solubilize the nodules. The absorbance of the resulting solution was measured at $570 \mathrm{~nm}$ (Synergy H1, Biotek). The percentage of calcium deposition for each experimental group was calculated based on the mean value of the control group as $100 \%$ of staining.

\section{Quantification of $\mathrm{H}_{2} \mathrm{O}_{2}$ diffusion}

The amount of $\mathrm{H}_{2} \mathrm{O}_{2}$ present in the extract was also quantified $(n=6)$. Aliquots of $100 \mu \mathrm{L}$ obtained from extracts of each group were transferred to tubes containing $900 \mu \mathrm{L}$ of acetate buffer solution ( $2 \mathrm{~mol} / \mathrm{L}, \mathrm{pH} 4.5$; Sigma Chemical Co.) to stabilize the $\mathrm{H}_{2} \mathrm{O}_{2}$. After that, an aliquot of $500 \mu \mathrm{L}$ of the buffer solution plus $\mathrm{H}_{2} \mathrm{O}_{2}$ from each tube was transferred to test tubes containing $2.2 \mathrm{~mL}$ of deionized water and $250 \mu \mathrm{L}$ of $0.5 \mathrm{mg} / \mathrm{mL}$ leucocrystal violet (Sigma Chemical Co.). The tubes were agitated, and a $50-\mu \mathrm{L}$ quantity of horseradish peroxidase enzyme solution ( $1 \mathrm{mg} / \mathrm{mL}$; Sigma Chemical Co.) was added. Then, aliquots of each tube were transferred to 96-well plates, and the optical density of the solutions was measured at 600-nm wavelength (Synergy H1, Biotek). A standard curve of known $\mathrm{H}_{2} \mathrm{O}_{2}$ concentrations was used for conversion of the optical density obtained in the samples into $\mu \mathrm{g}$ of $\mathrm{H}_{2} \mathrm{O}_{2}$ per $\mathrm{mL}$ of extract.

\section{Bleaching effectiveness}

For this analysis, prior to being bleached, the disks were subjected to a staining process with black tea to standardize the baseline color as previously described [11]. Disks with similar initial $L^{*}$ and $b^{*}$ values (CIE $L^{*} a^{*} b^{*}$ system) were randomly distributed into the control and experimental groups to obtain standardized samples $(n=6)$. In total, six sessions were performed for each protocol. Color readout was performed before bleaching (baseline) and $48 \mathrm{~h}$ after each session. The specimens were kept at $100 \%$ humidity at $37{ }^{\circ} \mathrm{C}$ before the first session $(48 \mathrm{~h}$ ) and during the interval between bleaching sessions ( $48 \mathrm{~h}$ ) to prevent dehydration. For reading, the disks were positioned in a white silicone matrix, leaving only the enamel surface exposed. A portable UV-Vis spectrophotometer (Color Guide 45/0; BYKGardner GmbH, Geretsried, Germany) was positioned over the sample, and three readings were made for calculation of the average. The values of $L^{*} a^{*} b^{*}$ were recorded, and the difference between $L^{*}, a^{*}$, and $b^{*}$ at the end of the experiment and at baseline was expressed as $\Delta \mathrm{L}, \Delta \mathrm{a}$, and $\Delta \mathrm{b}$. The overall color change of each specimen, expressed as $\Delta E$, was calculated according to the following equation: $\Delta E=\left[(\Delta L)^{2}+(\Delta a)^{2}+(\Delta b)^{2}\right]^{1 / 2}$.

\section{Statistical analysis}

For verification of the reproducibility of data, two independent experiments were performed for all protocols in this study. Thereafter, compiled data were subjected to Kolmogorov-Smirnov and Levene's tests for verification of normality and homoscedasticity. Data were analyzed by ANOVA complemented by Tukey's, Sidak's, and Dunnett's tests for multiple comparisons. All tests were set at a significance level of $5 \%$.

\section{Results}

\section{Cell viability/oxidative stress}

The results for MTT assay, SEM, and oxidative stress are demonstrated in Fig. 4. With the control group considered as $100 \%$ of cell viability, the percentages of viability for the IC group were 8.5, 37.6, 86.0, and $107.8 \%$ at $0 \mathrm{~h}$ and 12.0, 59.5, 170.2, and $270.3 \%$ at $72 \mathrm{~h}$, for the $35 \% 3 \times 15,10 \% 3 \times 15,10 \% 1 \times 15$, and $10 \% 1 \times 5$ protocols, respectively. For the PM group, the cell viability percentages were $15.3,71.0,127.2$, and $120.1 \%$ at $0 \mathrm{~h}$ and $22.4,159.8,252.0$, and $267.3 \%$ at $72 \mathrm{~h}$, for the $35 \% 3 \times 15$, $10 \% 3 \times 15,10 \% 1 \times 15$, and $10 \% 1 \times 5$ protocols, respectively. In the control group, the cell viability at the 72 -h period was 226.9 and $227.0 \%$ for the IC and PM groups, respectively. According to the graph in Fig. 3a, only the protocols 35 and $10 \% 3 \times 15$ with the IC and PM groups showed cell viability percentages significantly lower than that of the control group at $0 \mathrm{~h}(p<0.05)$. At $72 \mathrm{~h}$, this feature was observed for the protocols $35 \% 3 \times 15,10 \% 3 \times 15$, and $10 \% 1 \times 15$ in the IC group and for the protocols 35 and $10 \% 3 \times 15$ in the PM group $(p<0.05)$. Nevertheless, the cell viability values for the professional protocol $(35 \% 3 \times 15)$ were significantly lower than those of all experimental bleaching protocols with the $10 \% \mathrm{H}_{2} \mathrm{O}_{2}$ gel at 0 and $72 \mathrm{~h}$ in both groups $(p<0.05)$. The comparison of each protocol at both thicknesses between the time points showed no significant increase in cell viability for the 35 and $10 \%$ $3 \times 15$ protocols in the IC group and only for the $35 \% 3 \times 15$ protocol in the PM group $(p>0.05)$. Regarding the influence of disk thickness on cell viability, the cells exposed to $10 \% 3 \times 15$ 


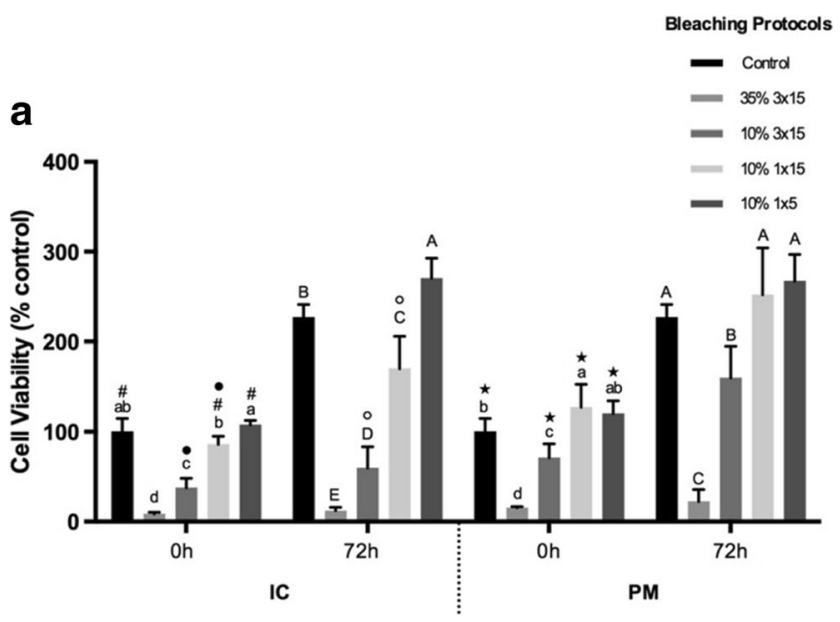

b

Bleaching Protocols

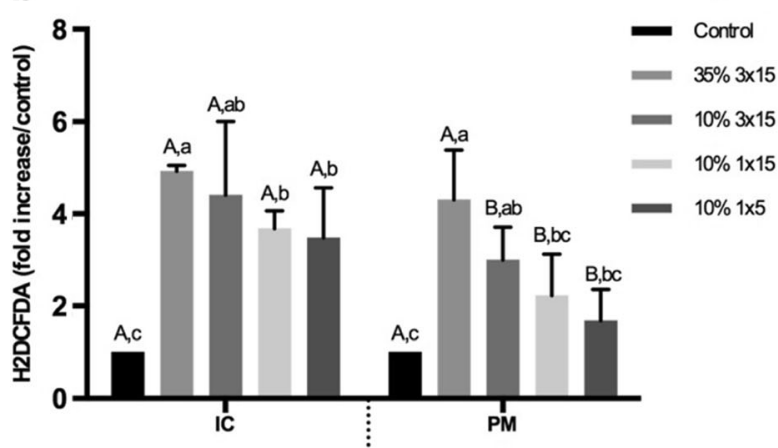

Fig. 4 a Bar graph of cell viability percentages obtained by MTT assay. Lowercase letters allow for comparison among bleaching protocols at $0 \mathrm{~h}$ for each thickness separately. Uppercase letters allow for comparison among bleaching protocols at $72 \mathrm{~h}$ for each thickness separately. Different letters demonstrate significant differences among groups (twoway ANOVA/Tukey's test; $p<0.05)$. Pound sign and star indicate significant differences between the time points $(0 \times 72 \mathrm{~h})$ for each protocol in the IC and PM groups, respectively (two-way ANOVA/ Tukey's test; $p<0.05$ ). Bullet and degree sign indicate significant differences between thicknesses (IC group $\times$ PM group) for each protocol at 0 and $72 \mathrm{~h}$, respectively (two-way ANOVA/Dunnett's test; $p<0.05)$. b Bar graph representative of the fold increase of $\mathrm{H}_{2}$ DCFDA fluorescence intensity normalized by the control group. Lowercase letters allow for comparison among the bleaching protocols for each thickness (IC group or PM group) (two-way ANOVA/Tukey's test). Uppercase letters allow for comparison between the thicknesses (IC group $\times$ PM group) for each bleaching protocol (two-way ANOVA/Sidak's test). Different letters demonstrate significant difference $(p<0.05)$

and $1 \times 15$ applied to the IC group at 0 and $72 \mathrm{~h}$ featured significantly lower cell viability percentages than those of the PM group $(p<0.05)$. HDPCs exposed to the extracts following all the bleaching protocols were under oxidative stress. The oxidative stress data are shown in Fig. 3b. The highest values for $\mathrm{H}_{2}$ DCFDA fluorescence intensity were observed for the professional bleaching protocol $(35 \% 3 \times 15 \mathrm{~min})$ for both tested thicknesses. For the IC group, significantly lower values in comparison with those of the traditional protocol were observed for the $10 \% \mathrm{H}_{2} \mathrm{O}_{2}$ gel applied for $1 \times 15$ and $1 \times 5 \min (p<0.05)$. Conversely, in the PM group, all protocols performed with the
$10 \% \mathrm{H}_{2} \mathrm{O}_{2}$ gel generated less intense oxidative stress conditions, since the values obtained were significantly lower than those observed for the professional bleaching protocol $(p<0.05)$. Regarding the disk thicknesses, significantly lower values were observed in the PM group relative to the IC group for the protocols performed with $10 \% \mathrm{H}_{2} \mathrm{O}_{2}$ bleaching gel $(p<0.05)$.

\section{Cell morphology}

Cell morphology images corroborated the data obtained by MTT assay (Fig. 5). In control group, a number of cells with a fibroblast-like shape could be observed covering the glass substrate at the 0 -h time point, in an $80 \%$ confluence pattern. Cells with large cytoplasm were observed, demonstrating that the HDPCs were capable of adhering and spreading onto the substrate. At $72 \mathrm{~h}$, the cells covered the entire glass surface. For the $35 \% 3 \times 15$ protocol, only cell debris were observed at 0 and $72 \mathrm{~h}$ for the IC group, demonstrating that death cells detached from the glass surface after interacting with toxic bleaching components. In PM group, the $35 \% 3 \times 15$ protocol also caused intense reduction of cells adhered to the glass, with several cell debris being observed spread on the substrate. Only a few cells with small cytoplasm remained attached to the substrate at both time points. When the $10 \% 3 \times 15$ protocol was performed, intense reduction in the number of cells was observed for IC group at both time points. Few cells with contracted cytoplasm were attached to the glass substrate at $72 \mathrm{~h}$. In PM group, reduced number of cells was observed; however, several cells with large cytoplasm remained adhered to the substrate at $0 \mathrm{~h}$, and an increased number of cells with fibroblast-like shape were observed at $72 \mathrm{~h}$. Regarding the $10 \% 1 \times 15$ protocol, a slight reduction on the number of cells that remained adhered to the glass surface occurred at the $0-\mathrm{h}$ time point for IC group, with most of cells featuring normal morphological shape. A great number of cells almost covering the entire glass surface was observed at $72 \mathrm{~h}$. Cell morphology similar to the negative control group at 0 and $72 \mathrm{~h}$ was observed for the $10 \% 1 \times 5$ protocol in the IC group and for $10 \% 1 \times 5$ and $1 \times 15$ protocols for PM group.

\section{ALP activity/mineralized nodule deposition}

For assessment of the regenerative potential of the HDPCs exposed to the extracts and the influence of the enamel/ dentin thicknesses on this feature, the ALP activity and mineralized nodule deposition were evaluated 14 and 21 days after bleaching, respectively. The professional protocol caused intense reduction in ALP activity for both thicknesses (IC and PM) compared with the negative control (Fig. 6a). However, a significant reduction in this cell parameter relative to the negative control was also observed for all tested protocols with the $10 \% \mathrm{H}_{2} \mathrm{O}_{2}$ bleaching gel. Only the protocol $10 \% 3 \times 15$ applied to the IC group showed no significant difference in 


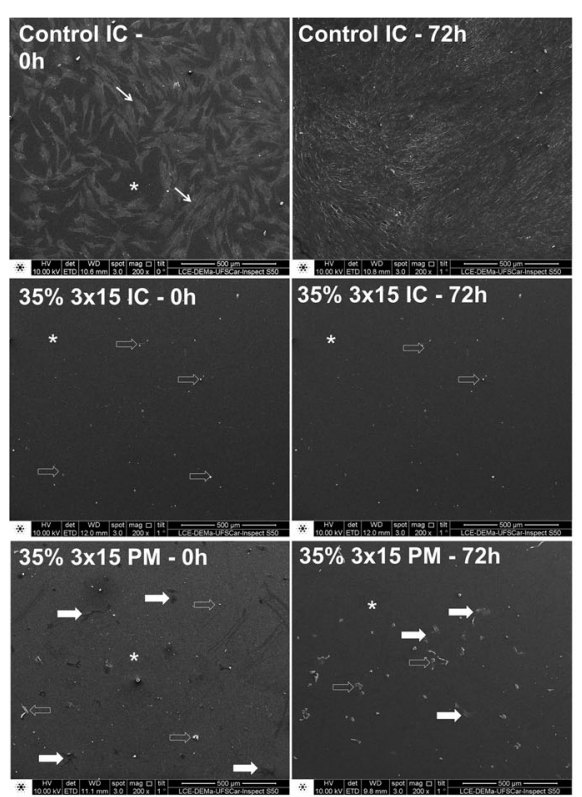

Fig. 5 Panel of representative SEM images for negative control group and bleached groups at both time points. It is possible to observe that the cells exposed to the $35 \% 3 \times 15$ protocol were intensely damaged, especially in the IC group. Only a few cells remained attached to the glass slide featuring intense alteration of their morphology. A reduction in the number of cells at $0 \mathrm{~h}$ associated with disruption of cell morphology was observed for the $10 \% 3 \times 15$ and $1 \times 15$ protocols in the IC group and

comparison with the professional protocol. When applied to the disks of the PM group, no significant difference among the tested protocols with the $10 \% \mathrm{H}_{2} \mathrm{O}_{2}$ gel was observed $(p>0.05)$. A significant difference between the IC and PM groups was observed for the $35 \% 3 \times 15,10 \% 3 \times 15$, and $10 \% 1 \times 15$ protocols $(p<0.05)$. Similar results were found for the Alizarin Red assay, where the 35 and $10 \% 3 \times 15$ bleaching protocols caused a more intense reduction of the mineralized nodule deposition in the IC group (Fig. 6b). For this assay, the $10 \% 1 \times 15$ and $1 \times 5$ bleaching protocols featured no significant alteration in mineralized nodule deposition compared with the control group in both tested thicknesses $(p>0.05)$

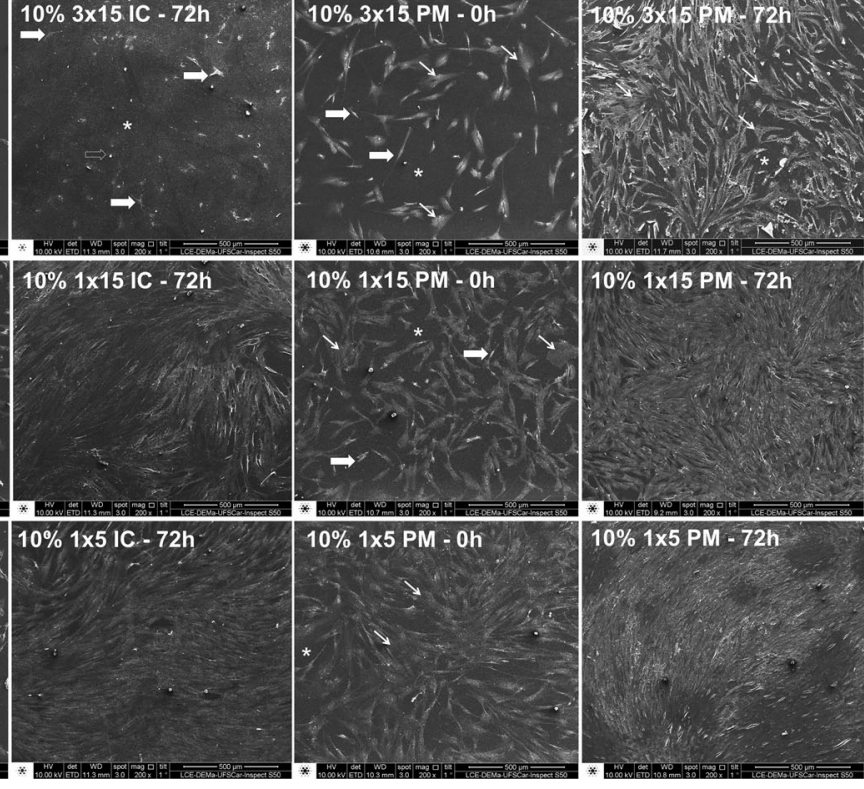

for the $10 \% 3 \times 15$ protocol in the PM group. The cells exposed to these protocols featured morphology at $72 \mathrm{~h}$ similar to the negative control group at $0 \mathrm{~h}$. Morphology similar to that of the negative control group at 0 and $72 \mathrm{~h}$ was observed for the $10 \% 1 \times 5$ protocol in the IC group, as well as for the $10 \% 1 \times 15$ and $1 \times 5$ protocols in the PM group. SEM $\times 200$

\section{$\mathrm{H}_{2} \mathrm{O}_{2}$ diffusion quantification}

The results of $\mathrm{H}_{2} \mathrm{O}_{2}$ quantification on the extracts are demonstrated in Fig. 7. The highest $\mathrm{H}_{2} \mathrm{O}_{2}$ values were found in the culture medium after application of the $35 \% \mathrm{H}_{2} \mathrm{O}_{2}$ gel for $3 \times 15 \mathrm{~min}$ in both tested thicknesses. However, a significantly lower $\mathrm{H}_{2} \mathrm{O}_{2}$ concentration was observed in the PM group for this professional protocol in comparison with the IC group. Regarding the IC group, the $\mathrm{H}_{2} \mathrm{O}_{2}$ diffusion was proportional to the contact time of the $10 \% \mathrm{H}_{2} \mathrm{O}_{2}$ bleaching gel on enamel, with a significant difference being observed among the groups. For the PM group, a similar feature was determined; however, no significant difference between the $10 \% 1 \times 15$

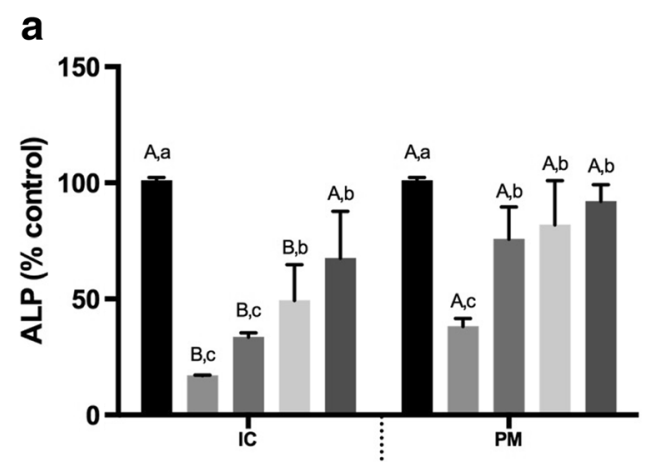

Fig. 6 a Bar graph representative of ALP activity. b Bar graph representative of Alizarin Red staining percentages. For both graphs, lowercase letters allow for comparison among the bleaching protocols for each thickness (IC group or PM group) (two-way ANOVA/Tukey's

b

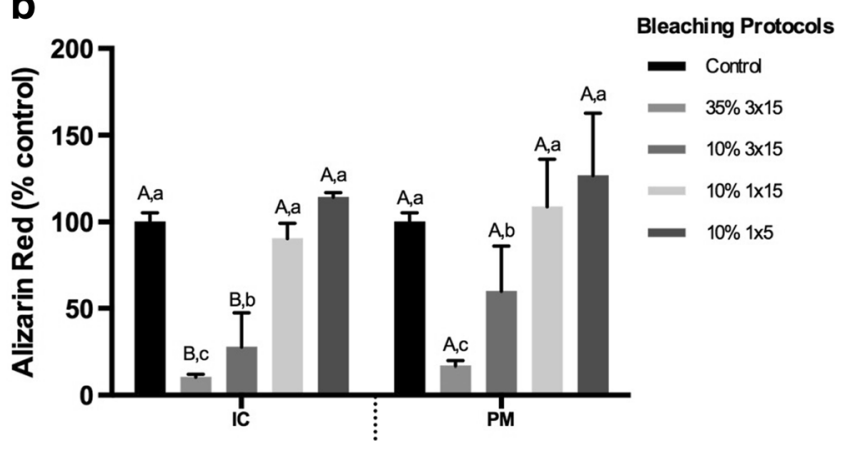

test). Uppercase letters allow for comparison between the thicknesses (IC group $\times$ PM group) for each bleaching protocol (two-way ANOVA/ Sidak's test). Different letters demonstrate significant differences $(p<0.05)$. All graphs were created with GraphPad Prism version 6 
Bleaching Protocols

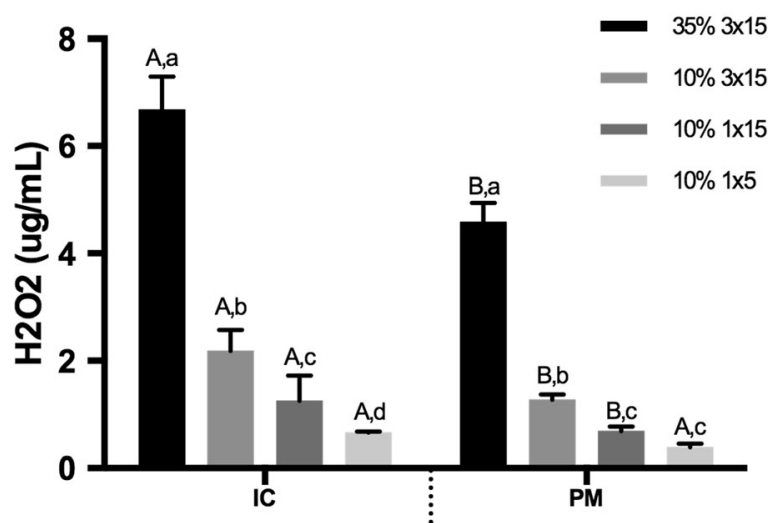

Fig. 7 Bar graph representative of $\mathrm{H}_{2} \mathrm{O}_{2}(\mu \mathrm{g} / \mathrm{mL})$ present on extracts. Lowercase letters allow for comparison among the bleaching protocols for each thickness (IC group or PM group) (two-way ANOVA/Tukey's test). Uppercase letters allow for comparison between the thicknesses (IC group $\times$ PM group) for each bleaching protocol (two-way ANOVA/ Sidak's test). Different letters demonstrate significant differences $(p<0.05)$. Graph was created with GraphPad Prism version 6

and $10 \% 1 \times 5$ protocols was observed. Significantly higher $\mathrm{H}_{2} \mathrm{O}_{2}$ diffusion in the IC relative to the PM group was detected for the $10 \% 3 \times 15$ and $1 \times 15$ protocols $(p<0.05)$.

\section{Color analysis}

First, data from the traditional protocol $(35 \% 3 \times 15)$ for the IC and PM groups were analyzed throughout the six bleaching sessions to achieve saturation. It was possible to observe that the specimens reached color alteration saturation after the second (S2) and fifth (S5) bleaching sessions for the IC and PM groups, respectively, since no significant difference was observed with the following sessions beyond this point $(p<0.05)$ (Fig. 8). Therefore, the $\Delta E$ values for $35 \%$ $3 \times 15$ at session two (S2) and $35 \% 3 \times 15$ at session five (S5) were used as positive controls for the IC and PM groups, respectively, for the following analysis. To achieve the number of sessions for each experimental protocol with the $10 \% \mathrm{H}_{2} \mathrm{O}_{2}$ gel capable of promoting the same bleaching effectiveness as the traditional protocol at the saturation point, the $\Delta E$ values for each protocol at each bleaching session were compared with those of the positive control groups (Fig. 9). According to this analysis, no significant difference with both positive control groups (IC and PM) was observed for the following protocols: (1) IC group $-10 \% 3 \times 15$ at S4, S5, and S6 and $10 \% 1 \times 15$ at S6 and (2) PM group $-10 \% 3 \times 15$ at S6. The number of sessions needed for each experimental protocol to achieve the same bleaching pattern as with the traditional protocol for each thickness is demonstrated in Table 1. In this experiment, nonbleached disks from the IC and PM groups were used as negative control, and no significant alteration in $\Delta E$ was observed throughout the 6 time points (data not shown).

\section{Discussion}

Previous studies demonstrated that the depth of dentin color alteration after tooth bleaching was greater in anterior than in

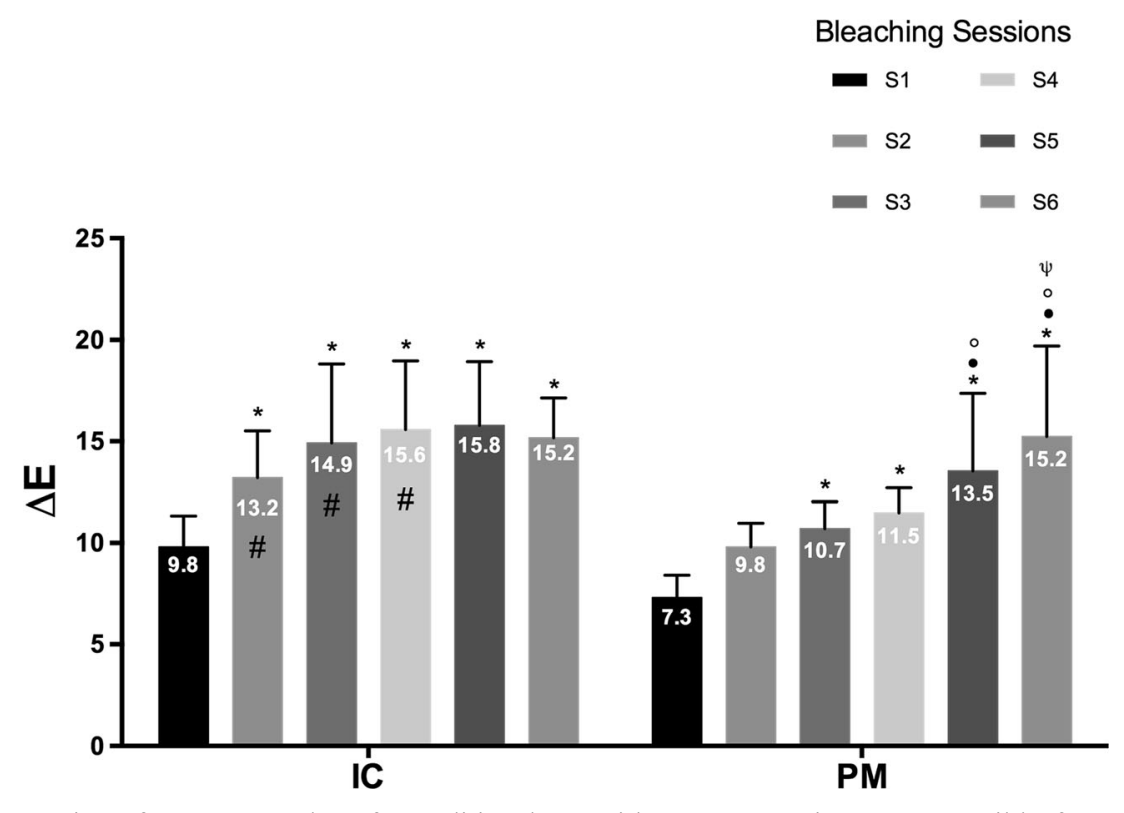

Fig. 8 Bar graph representative of mean $\Delta E$ values for traditional protocol $(35 \% 3 \times 15)$ throughout the bleaching sessions for thin and thick disks. Values inside bars represent the mean $\Delta E$ for each bleaching session $(S)$. Asterisk indicates significant difference with $\mathrm{S} 1$, bullet indicates significant difference with $\mathrm{S} 2$, degree sign indicates significant difference with $\mathrm{S} 3$, and psi indicates significant difference with S4. Comparisons are possible for each thickness separately (Tukey's test; $p<0.05$ ). Pound sign indicates significant difference between thicknesses (IC group $\times$ PM group) at each bleaching session (Sidak's test; $p<0.05$ ). Graph was created with GraphPad Prism version 6 
Fig. 9 Bar graph representative of mean $\Delta E$ values of positive control at saturation point and for experimental protocols throughout the six bleaching sessions. Comparisons are possible between positive controls and experimental protocols at each bleaching session. Asterisk indicates significant difference with the PM group as positive control (35\% $3 \times 15$ S5); bullet indicates significant difference with the IC group as positive control $(35 \%$ $3 \times 15$ S2) (Sidak's test; $p<0.05$ ). Graph was created with GraphPad Prism version 6

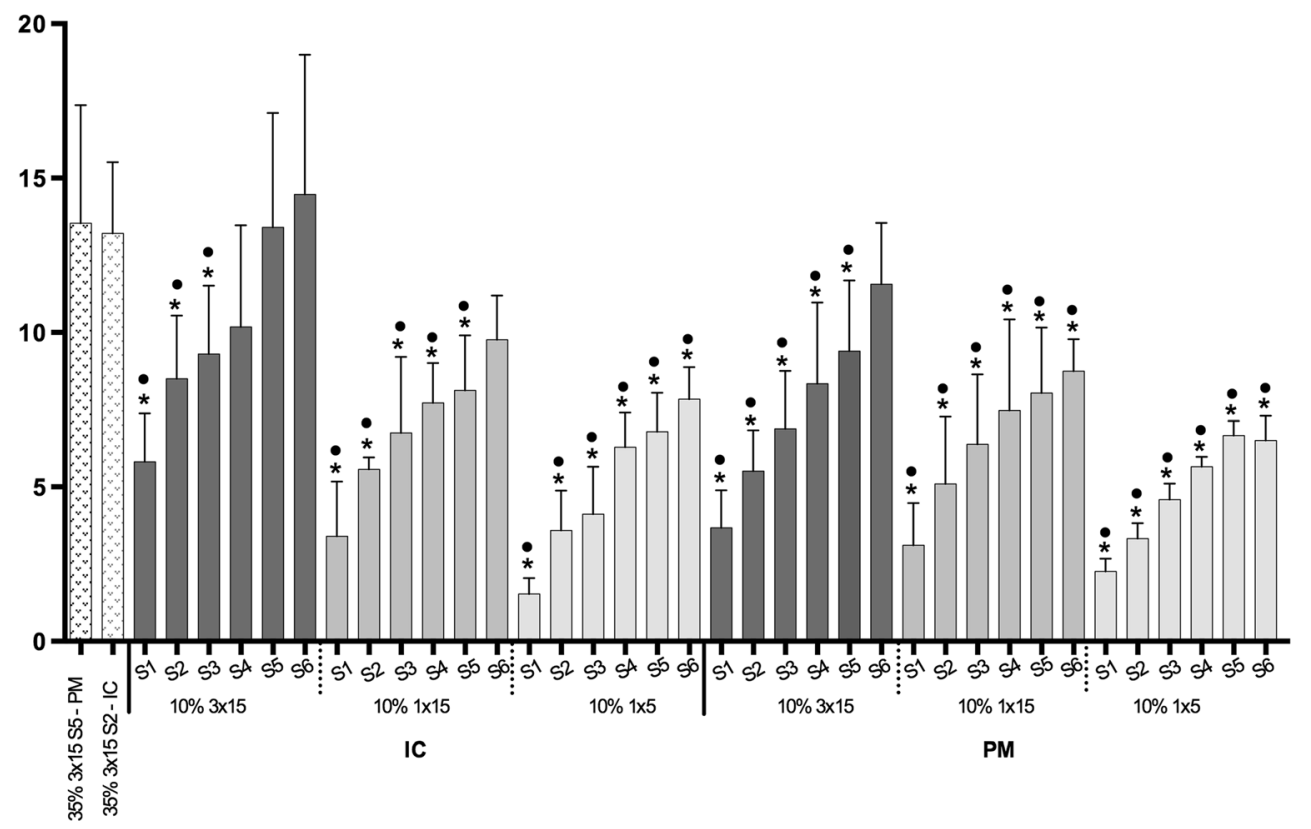

posterior teeth [3]. It was also shown that patients subjected to professional tooth bleaching $(35 \% 3 \times 15)$ reported hypersensitivity in $0 \%$ of premolars, $30 \%$ of canines, $53.3 \%$ of central incisors, and $76.7 \%$ of lateral incisors [2]. Therefore, in the present investigation, the influence of tooth thickness on trans-enamel and trans-dentinal cytotoxicity of a $10 \% \mathrm{H}_{2} \mathrm{O}_{2}$ gel on human dental pulp cells was evaluated, as well as the whitening effectiveness of that gel applied for variable number of sessions. Therefore, enamel/dentin disks with 2.3- and 4.0$\mathrm{mm}$ thicknesses were obtained to simulate mandibular ICs and PMs, respectively.

Previous studies [8, 12-14] demonstrated that performing professional bleaching protocol $\left(35 \% \mathrm{H}_{2} \mathrm{O}_{2} \mathrm{gel}\right.$ for $3 \times 15 \mathrm{~min}$ ) onto enamel/dentin disks with $3.5-\mathrm{mm}$ thickness, simulating maxillary central incisors, reduced dramatically the HDPC viability and caused intense changes in the cell morphology. In the present investigation, this protocol was also capable of causing similar toxicity when applied onto 2.3- (IC group) and 4.0-mm-thick (PM groups) enamel/dentin disks. These effects have been correlated with the occurrence of pathologic oxidative stress conditions, leading to cell death by necrosis after disruption of cell membrane $[8,12]$. In the present study, we also detected intense positive staining for an $\mathrm{H}_{2}$ DCFDA probe on HDPCs exposed to the extracts obtained from the professional protocol, confirming that the pathway for cell viability reduction mediated by tooth bleaching is related to the establishment of oxidative stress. These cells featured limited proliferative potential 3 days after bleaching, since no significant difference between 0 and $72 \mathrm{~h}$ was observed in both IC and PM groups. The negative effects of professional therapy on pulp cells took place due to the intense diffusion of nonreacted $\mathrm{H}_{2} \mathrm{O}_{2}$ through enamel/dentin, which was inversely proportional to the tooth thickness. All experimental bleaching protocols performed with the $10 \% \mathrm{H}_{2} \mathrm{O}_{2}$ gel also resulted in trans-enamel and trans-dentinal diffusion of $\mathrm{H}_{2} \mathrm{O}_{2}$, which was directly related to contact time and specimen thickness. Conversely, this phenomenon was 3 to 12 times less intense than that observed for the professional bleaching protocol $(35 \%$ $3 \times 15$ ). For both tested thicknesses, a significant reduction in cell viability in comparison with that of the non-bleached control group was found only when the $10 \% \mathrm{H}_{2} \mathrm{O}_{2}$ gel was applied following the $3 \times 15$-min protocol. This bleaching protocol induced more intense oxidative stress and consequently cell viability reduction in the IC group, demonstrating that the enamel/ dentin thickness of the dental substrate plays a significant role in bleaching-induced toxicity. Differences in cell morphology regarding the disk thickness for this protocol were also observed by SEM analysis. A reduced number of cells adhering to glass slides featuring more intense alteration in morphology was detected in the IC group at $0 \mathrm{~h}$. For the PM group at $72 \mathrm{~h}$, the cells presented significant increased viability in comparison with those cells at $0 \mathrm{~h}$, which exhibited morphology similar to that of the negative control at $\mathrm{T} 1$.

When the contact time of the $10 \% \mathrm{H}_{2} \mathrm{O}_{2}$ gel with enamel was reduced to 15 or $5 \mathrm{~min}$, no significant decrease in cell viability relative to that of the negative control group was observed for both thicknesses. A slight decrease in cell viability (14\%) occurred for the $1 \times 15$ protocol in the IC group associated with a reduced number of cells at $0 \mathrm{~h}$. In the IC group, oxidative stress was still detected in those HDPCs exposed to the $10 \% \mathrm{H}_{2} \mathrm{O}_{2} 1 \times 15$ and $1 \times 5$ protocols; however, no significant difference from the negative control was observed when these experimental protocols were performed in the PM group. De Souza Costa et al. [7] demonstrated that a $38 \% \mathrm{H}_{2} \mathrm{O}_{2}$ gel applied for $45 \mathrm{~min}$ to sound mandibular incisors from young patients (dentin thickness $=1.82 \pm 0.08 \mathrm{~mm}$ ) caused intense 
pulpal damage in about $75 \%$ of the samples. In contrast, pulps of premolars (dentin thickness $=3.10 \pm 0.11 \mathrm{~mm}$ ) subjected to the same professional bleaching protocol did not exhibit pulp damage. Also, only patients who had their incisors bleached reported tooth sensitivity [7]. Another in vivo investigation currently performed [5] showed the occurrence of partial pulp necrosis in $60 \%$ of mandibular incisors of elderly patients (from 54 to 62 years old; mean $58.2 \pm 4.3$ ) in comparison with $100 \%$ of young patients (from 18 to 30 years old; mean $20.1 \pm 4.3$ ) after in-office bleaching therapy. Additionally, areas of pulp necrosis were larger in young teeth. The main dentin thicknesses for the elderly and young patients were $1.99 \pm 0.10$ and $1.77 \pm 0.08$, respectively [5]. Therefore, based upon the scientific data previously obtained in these clinical trials $[5,7]$ and laboratorial studies [8, 12-14], as well as in accordance with the results of the present investigation, it is possible to state that enamel/dentin thickness plays a role in $\mathrm{H}_{2} \mathrm{O}_{2}$ diffusion across hard tooth structures, and this is inversely proportional to the toxic effects caused by bleaching gel components on pulp cells.

To assess the regenerative potential of HDPCs over time, we evaluated the expression of two standard predictors of odontoblastic differentiation potential, the ALP activity and mineralized nodule deposition. According to several in vitro investigations, $\mathrm{HDPCs}$ under intense oxidative stress triggered by $\mathrm{H}_{2} \mathrm{O}_{2}$ have odontoblastic marker expression, such as ALP, DSPP, DMP-1, and mineralized nodule deposition, down-regulated. Conversely, non-toxic concentrations of $\mathrm{H}_{2} \mathrm{O}_{2}$ enhanced the expression of such markers [15-18]. Thus, the lower the concentration of $\mathrm{H}_{2} \mathrm{O}_{2}$ in contact with pulp cells after tooth bleaching, the higher the regenerative capability of human pulp tissue to overcome the oxidative damage. As expected in the present study, the HDPCs showed drastically reduced ALP activity and mineralized nodule deposition when exposed to the professional bleaching protocol; this was more evident in the IC than in PM group. Regarding the $10 \% \mathrm{H}_{2} \mathrm{O}_{2}$ gel, odontoblastic marker expression was proportional to the contact time and to the enamel/dentin thickness. Reduction of ALP activity at 14 days was observed for all tested bleaching protocols relative to the negative control group. At 21 days, disturbance of mineralized nodules deposition was observed only for the $10 \%$ $\mathrm{H}_{2} \mathrm{O}_{2} 3 \times 15$-min protocol. Indeed, the $10 \% 1 \times 5$ protocol for the IC group and the $10 \% 1 \times 15$ and $1 \times 5$ protocols for the PM group featured higher mineralized matrix deposition than did the negative control. Previous studies demonstrated that low concentrations of $\mathrm{H}_{2} \mathrm{O}_{2}$ are capable of stimulating cells to express proteins related to the deposition and mineralization of dentin matrix; these positive cellular effects were associated with the low-intensity oxidative stress generated by reduced quantity of $\mathrm{H}_{2} \mathrm{O}_{2}$ [15-17]. Analysis of these data demonstrates that human dental pulp cells are capable of regulating oxidative stress, depending on its intensity, which may modulate their secretory activity.
It has been demonstrated that whitening efficacy may be compromised when low concentrations of bleaching gels are used [14]. Nevertheless, Sulieman et al. [19] reported that gels with $25,15,10$, and $5 \% \mathrm{H}_{2} \mathrm{O}_{2}$ were capable of achieving the same bleaching pattern (B1, VITA scale) as the gel with $35 \%$ $\mathrm{H}_{2} \mathrm{O}_{2}$ if the number of sessions was increased. To determine the bleaching potential of the experimental protocols in comparison with that of the traditional in-office professional therapy, we performed a total of six bleaching sessions using the $35 \%$ $\mathrm{H}_{2} \mathrm{O}_{2}$ gel for $3 \times 15$ min on IC and PM disks, with 48-h intervals. The collected data were subjected to statistical analysis for assessment of the saturation point for this protocol in both thicknesses. Under the experimental conditions of this in vitro study, the IC disks reached the saturation point after two bleaching sessions ( $\mathrm{S} 2-\Delta E=13.2)$. This feature was reached after five sessions for the PM disks ( $\mathrm{S} 5-\Delta E=13.5$ ). After that, the $\Delta E$ values obtained for the experimental protocols throughout the six bleaching sessions (S1 to S6) were compared with the two positive control values. This analysis allowed us to determine the number of sessions needed to achieve color alteration statistically similar to that achieved with the professional protocol at saturation point. According to the results, the $10 \%$ $3 \times 15$ and $1 \times 15$ protocols applied in the IC group were capable of achieving the same pattern as the professional protocol after four and six sessions, respectively. For the PM group, six sessions with the $10 \% \mathrm{H}_{2} \mathrm{O}_{2}$ gel applied for $3 \times 15 \mathrm{~min}$ were needed to promote a bleaching outcome as effective as that with the professional protocol (positive control). Then, only a few additional sessions with the less aggressive bleaching protocols $\left(10 \% \mathrm{H}_{2} \mathrm{O}_{2}\right.$ gel) are needed to achieve an esthetic outcome similar to that of the professional protocol applied to teeth of greater thickness. Based on the whitening effectiveness observed in the present study, one may consider that bleaching gels with low concentrations of $\mathrm{H}_{2} \mathrm{O}_{2}$ appear to be an interesting alternative for professional tooth bleaching in teeth with thin enamel and dentin substrate, such as mandibular incisors.

However, it is important to notice that in vitro studies do not reflect the real conditions found in vivo, where the pulpal pressure and organic components inside the dentinal tubules and extracellular matrix effectively minimize the negative effects of bleaching gel components on pulp tissue [6,7]. Nevertheless, previous studies demonstrated that professional in-office bleaching therapies cause no damage to pulp tissue of premolar teeth, whereas our results demonstrated intense damage to pulp cells even when this simulated therapy was applied to PM disks $[6,7]$. The thinner enamel present in bovine disks from PM group in comparison to human premolars may have influenced the in vitro toxicity observed. On the other hand, Camargo et al. [20] demonstrated that human teeth are more permeable do $\mathrm{H}_{2} \mathrm{O}_{2}$ than bovine teeth. It is important to report that the enamel/dentin thicknesses simulated in the present investigation are relative to the central area of buccal surface of human tooth. At the cervical area, the enamel thickness is very thin, 
which makes it a very permeable surface [21]. Also, depending on the anatomical morphology of the cementoenamel junction, exposed dentin areas may contact the bleaching gel. These features may play a role on $\mathrm{H}_{2} \mathrm{O}_{2}$ diffusion when dental barrier misplaced leaving cervical area exposed, since dentin and enamel/dentin substrate are more permeable to $\mathrm{H}_{2} \mathrm{O}_{2}$ than cementum [22]. Also, in the present study, the whitening effectiveness analysis was performed in intensely stained samples to simulate a challenging situation [23]. In this way, since all these factors may play a role in tooth sensitivity and bleaching effectiveness, the results observed in the present investigation should be interpreted with caution. Therefore, in spite of the positive results that we found for the $10 \% \mathrm{H}_{2} \mathrm{O}_{2}$ gel are encouraging, further in vivo studies and clinical trials should be performed to assess the esthetic outcome and biocompatibility of these alternative in-office protocols, which may determine some safe and effective professionally guided bleaching therapies in the near future.

\section{Conclusions}

Enamel/dentin thickness plays a significant role in the transenamel and trans-dentinal cytotoxicity of a $10 \% \mathrm{H}_{2} \mathrm{O}_{2}$ bleaching gel to human dental pulp cells. In addition, the application of this gel for 45 or 15 min on enamel-dentin disks prepared to mimic mandibular human incisors decreased significantly cell toxicity in comparison with that caused by highconcentrated gels $\left(35 \% \mathrm{H}_{2} \mathrm{O}_{2}\right)$ and determined a similar esthetic outcome when the number of bleaching sessions was increased.

Acknowledgments The authors acknowledge the São Paulo Research Foundation-FAPESP (grant \#2014/07229-6), the National Council for Scientific and Technological Development-CNPq (grants \#442336/ 2014-4 and 303599/2014-6), and the Brazilian Division of the IADR award (1st place, PRONAC/2014) for the financial support.

\section{Compliance with ethical standards}

Conflict of interest The authors declare that they have no conflict of interest.

Ethical approval This study was approved by the Research Ethics Committee of the Araraquara Dental School/UNESP, São Paulo, Brazil (Proc. $\mathrm{N}_{-}^{\mathrm{o}}$ 3467314.0.0000.5416). All procedures performed in studies involving human participants were in accordance with the ethical standards of the institutional and/or national research committee and with the 1964 Helsinki declaration and its later amendments or comparable ethical standards.

Informed consent Informed consent was obtained from all individual participants included in the study.

\section{References}

1. de Almeida LC, Costa CA, Riehl H, dos Santos PH, Sundfeld RH, Briso AL (2012) Occurrence of sensitivity during at-home and in- office tooth bleaching therapies with or without use of light sources. Acta Odontol Latinoam 25:3-8

2. Bonafé E, Bacovis CL, Iensen S, Loguercio AD, Reis A, Kossatz S (2013) Tooth sensitivity and efficacy of in-office bleaching in restored teeth. J Dent 41:363-369

3. Rodrigues LM, Vansan LP, Pécora JD, Marchesan MA (2009) Permeability of different groups of maxillary teeth after $38 \%$ hydrogen peroxide internal bleaching. Braz Dent J 20:303-306

4. Roderjan DA, Stanislawczuk R, Hebling J, de Souza Costa CA, Reis A, Loguercio AD (2015) Response of human pulps to different in-office bleaching techniques: preliminary findings. Braz Dent $\mathrm{J}$ 26:242-248

5. Roderjan DA, Stanislawczuk R, Hebling J, de Souza Costa CA, Soares DG, Reis A, Loguercio AD (2014) Histopathological features of dental pulp tissue from bleached mandibular incisors. J Mater Sci Eng B 4:178-185

6. Kina JF, Huck C, Riehl H, Martinez TC, Sacono NT, Ribeiro AP, Costa CA (2010) Response of human pulps after professionally applied vital tooth bleaching. Int Endod J 43:572-580

7. De Souza Costa CA, Riehl H, Kina JF, Sacono NT, Hebling J (2010) Human pulp responses to in-office tooth bleaching. Oral Surg Oral Med Oral Pathol Oral Radiol Endod 109:e59-e64

8. Soares DG, Basso FG, Hebling J, de Souza Costa CA (2014) Concentrations of and application protocols for hydrogen peroxide bleaching gels: effects on pulp cell viability and whitening efficacy. J Dent 42:185-198

9. Soares DG, Basso FG, Hebling J, de Souza Costa CA (2015) Immediate and late analysis of dental pulp stem cells viability after indirect exposition to alternative in-office bleaching strategies. Clin Oral Investig 19:1013-1020

10. Hanks CT, Craig RG, Diehl ML, Pashley DH (1998) Cytotoxicity of dental composites and other materials in a new in vitro device. $\mathrm{J}$ Oral Pathol 17:396-403

11. Gronthos S, Arthur A, Bartold PM, Shi S (2011) A method to isolate and culture expand human dental pulp stem cells. Methods Mol Biol 698:107-121

12. Soares DG, Basso FG, Scheffel DS, Hebling J, de Souza Costa CA (2015) Responses of human dental pulp cells after application of a lowconcentration bleaching gel to enamel. Arch Oral Biol 60:1428-1436

13. Soares DG, Ribeiro AP, da Silveira VF, Hebling J, de Souza Costa CA (2013) Efficacy and cytotoxicity of a bleaching gel after short application times on dental enamel. Clin Oral Investig 17:1901-1909

14. Soares DG, Basso FG, Pontes EC, Garcia Lda F, Hebling J, de Souza Costa CA (2014) Effective tooth-bleaching protocols capable of reducing $\mathrm{H}(2) \mathrm{O}(2)$ diffusion through enamel and dentine. J Dent 42:351-358

15. Lee DH, Lim BS, Lee YK, Yang HC (2006) Effects of hydrogen peroxide $(\mathrm{H} 2 \mathrm{O} 2)$ on alkaline phosphatase activity and matrix mineralization of odontoblast and osteoblast cell lines. Cell Biol Toxicol 22:39-46

16. Min KS, Lee HJ, Kim SH, Lee SK, Kim HR, Pae HO (2008) Hydrogen peroxide induces Heme Oxygenase-1 and dentin sialophosphoprotein mRNA in human pulp cells. J Endod 34:983-989

17. Matsui S, Takahashi C, Tsujimoto Y, Matsushima K (2009) Stimulatory effects of low-concentration reactive oxygen species on calcification ability of human dental pulp cells. J Endod 35:67-72

18. Lee YH, Kang YM, Heo MJ, Kim GE, Bhattarai G, Lee NH, Yu MK, Yi HK (2013) The survival role of peroxisome proliferator-activated receptor gamma induces odontoblast differentiation against oxidative stress in human dental pulp cells. J Endod 39:236-241

19. Sulieman M, Addy M, MacDonald E, Rees JS (2004) The effect of hydrogen peroxide concentration on the outcome of tooth whitening: an in vitro study. J Dent 32:295-299

20. Camargo SE, Valera MC, Camargo CH, Gasparoto Mancini MN, Menezes MM (2007) Penetration of $38 \%$ hydrogen peroxide into 
the pulp chamber in bovine and human teeth submitted to office bleach technique. J Endod 33:1074-1077

21. Chen JH, Xu JW, Shing CX (1993) Decomposition rate of hydrogen peroxide bleaching agents under various chemical and physical conditions. J Prosthet Dent 69:46-48

22. Palo RM, Bonetti-Filho I, Valera MC, Camargo CH, Camargo S, Moura-Netto C, Pameijer C (2012) Quantification of peroxide ion passage in dentin, enamel, and cementum after internal bleaching with hydrogen peroxide. Oper Dent 37:660-664

23. Duque CC, Soares DG, Basso FG, Hebling J, de Souza Costa CA (2014) Bleaching effectiveness, hydrogen peroxide diffusion, and cytotoxicity of a chemically activated bleaching gel. Clin Oral Investig 18:1631-1637 